\title{
ENSINO DE PORTUGUÊS COMO LÍNGUA ESTRANGEIRA NO SUDESTE DO PARÁ
}

Portuguese as a foreign language teaching in the southeast of Pará

\author{
Tania Maria Moreira* \\ Camila Solino Rodrigues** \\ Roberta Morgana Petry ${ }^{* * *}$
}

\begin{abstract}
RESUMO: O presente trabalho compartilha um conjunto de reflexões acerca do ensino e da aprendizagem de Língua Portuguesa para alunos estrangeiros da pós-graduação, na Unifesspa, no período de 2015 a 2016. Essa foi uma ação pioneira realizada na instituição, por meio do Idiomas Sem Fronteiras, orientada segundo uma visão de linguagem como interação, noção de gênero como ação social estruturada em etapas para atingir uma finalidade e mesclou noções de ensino de leitura instrumental com estudos do Interacionismo Sócio-Discursivo e da Escola de Sydney, no ensino de gêneros que circulam em ambientes acadêmicos, tendo como base os estudos de Almeida Filho (2007, 2012, 2015), Oliveira e Silva (2018), Halliday (1978, 1994), dentre outros. Nesses termos, discorre-se sobre os princípios norteadores do ensino, apresentase o plano de trabalho utilizado e reportam-se alguns resultados dessa experiência. Em termos de ensino, a abordagem adotada no curso teve boa aceitação pelos aprendizes e promoveu a aprendizagem, tendo em vista que proporcionou a aprovação de alunos no exame de proficiência em Língua Portuguesa. Em termos de formação de professores, o curso desenvolvido se figurou como um primeiro passo para a realização de novos estudos e práticas de ensino e elaboração de materiais didáticos em Português como Língua Estrangeira (PLE).
\end{abstract}

PALAVRAS-CHAVE: Ensino e aprendizagem de PLE. Gênero como ação social. Interacionismo Sócio-Discursivo. Escola de Sidney.

\begin{abstract}
The following article shares an array of reflections regarding Portuguese Language learning and teaching to foreign graduate students, at Unifesspa, from 2015 to 2016. This was a pioneering experience held at the institution through Language Without Borders Program which followed, as a theoretical basis, the perspective of language as interaction and the notion of genre as a social action structured in stages to achieve a purpose and merged notions of instrumental reading teaching with Socio-Discursive Interactionismand Sydney School studies, focusing on teaching genres that circulate in academic environments, based on the studies of Almeida Filho (2007, 2012, 2015), Oliveira e Silva (2018), Halliday (1978, 1994), among others. In that way, we will discuss the guiding principles of teaching, showing the schedule and the working plan that were used and reporting some results of this experience. In terms of teaching, the chosen approach was well accepted by the students, considering that provided the approval of the students in the Portuguese proficiency exam. In terms of teacher's formation, the developed course was a first step toward their studies in Portuguese as a Foreign Language, regarding teaching practices and teaching materials development.
\end{abstract}

KEYWORDS: Teaching Portuguese as a Foreign Language. Genre as a Social Action. Socio-Discursive Interactionism. Sydney School.

\footnotetext{
*Doutora em Letras pela Universidade Federal de Santa Maria (UFSM), Professora e pesquisadora da Universidade Federal do Sul e Sudeste do Pará (UNIFESSPA) e em exercício provisório no Departamento de Letras Estrangeiras Modernas da UFSM.

** Mestranda do Programa de Pós-Graduação em Letras da Universidade Federal do Sul e Sudeste do Pará (Unifesspa).

*** Graduanda do curso de Letras-Português da Universidade Federal de Santa Maria (UFSM).
} 


\section{Introdução}

O ensino de Português, como Língua Adicional, Segunda Língua, Língua de Herança etc., compõe uma área de estudo que ainda não possui, no meio acadêmico brasileiro, o espaço e a divulgação proporcional à sua importância. Atualmente, os processos para internacionalização de Instituições de Ensino Superior (IES) e Institutos de Pesquisa (IP) em vigência, no Brasil, são incentivados por ações como o Programa Institucional de Internacionalização (PrInt), promovido pela Coordenação de Pessoal de Nível Superior (Capes), que engloba o âmbito dos programas de pós-graduação (PPG).

A partir desse atual contexto nas universidades brasileiras, nota-se uma necessidade de elaboração de programas para o ensino de idiomas, em especial, o Português como Língua Estrangeira (PLE), visando suprir a demanda de uma nova comunidade acadêmica, os estrangeiros. A Unifesspa, por exemplo, localizada na região Norte do país, com sede na cidade de Marabá-PA, é uma instituição de ensino superior pública, multicampi, resultante do desmembramento do campus de Marabá da Universidade Federal do Pará (UFPA), em junho de 2013, que está situada no contexto amazônico e atrai diversos pesquisadores estrangeiros para a realização de estudos interdisciplinares que se relacionam, muitas vezes, às lutas sociais, às questões ambientais, geográficas, antropológicas e históricas da região; dentre outras temáticas.

Com o fomento à internacionalização, alunos de diferentes faixas etárias chegam ao Brasil, inclusive na própria Unifesspa, sem dominar o idioma local e enfrentam diversas dificuldades de comunicação, compreensão, relação social e problemas no processo de aprendizagem acadêmica. Assim, as IES estão cada vez mais buscando uma integração de culturas para o melhor desenvolvimento dos estudos e relações sociais da sua comunidade acadêmica. Segundo o próprio site da Fundação Capes, os objetivos desse processo de internacionalização incluem ainda:

[...] Fomentar o desenvolvimento de Planos Estratégicos de Internacionalização como meio de melhorar a qualidade dos cursos de pósgraduação brasileiros e de conferir maior visibilidade à pesquisa científica realizada no Brasil; incentivar o estabelecimento de redes de pesquisa internacionais integradas por IES/IP brasileiras; tornar mais flexível e ampliar o apoio à internacionalização dos PPGs brasileiros; promover a mobilidade internacional de professores, pesquisadores e estudantes de pósgraduação; aumentar a atratividade de professores, pesquisadores e estudantes de pós-graduação estrangeiros para as IES/IP brasileiras (CAPES, 2017). 
Para alcançar esses objetivos, as IES do Brasil têm promovido cursos para fins de aprendizagem de Língua Portuguesa voltados para alunos que não têm esse idioma como primeira língua. Tais cursos visam ao aprimoramento da aprendizagem do idioma, por parte dos estrangeiros que aqui chegam e precisam se preparar para o exame obrigatório de proficiência da Língua Portuguesa, o Celpe-Bras ${ }^{1}$, tal como a realização de atividades acadêmicas bem-sucedidas. Consequentemente, essas ações facultam ao aluno a possibilidade de uso do idioma local na comunicação diária.

A partir desse desenho da realidade acadêmica atual, é cada vez maior a necessidade de se ampliarem os estudos críticos sobre a área do ensino de Português como Língua NãoMaterna; de proporcionar uma maior divulgação de pesquisas na área; de produção de artigos científicos, de livros e materiais didáticos; além de incentivar a realização de cursos para suprir a necessidade da comunidade acadêmica das IES, tal como ocorreu na Unifesspa, visando à adequação do ensino de alunos de diferentes faixa etárias, formações acadêmicas e nacionalidades.

Tendo em vista que o curso $^{2}$ para fins de aprendizagem de Língua Portuguesa, direcionado aos alunos estrangeiros da pós-graduação, na Unifesspa, foi uma experiência pioneira realizada na instituição, por meio do Idiomas Sem Fronteiras, no presente trabalho, tem-se por objetivo compartilhar um conjunto de reflexões acerca do ensino e da aprendizagem de Língua Portuguesa para alunos estrangeiros da pós-graduação, na Unifesspa, no período de 2015 a 2016. Nesses termos, além desta introdução e das considerações finais, discorre-se sobre os princípios norteadores da experiência, reportam-se o plano de trabalho, algumas ações de ensino envolvendo o gênero artigo de opinião e alguns resultados alcançados com essa experiência.

\footnotetext{
${ }^{1}$ Exame que "[...]possibilita a Certificação de Proficiência em Língua Portuguesa para Estrangeiros. Desenvolvido e outorgado pelo Ministério da Educação (MEC), aplicado no Brasil e em outros países com o apoio do Ministério das Relações Exteriores (MRE) é o único certificado de proficiência em português como língua estrangeira reconhecido oficialmente pelo governo do Brasil. Internacionalmente, é aceito em empresas e instituições de ensino como comprovação de competência na língua portuguesa e no Brasil é exigido pelas universidades para ingresso em cursos de graduação e em programas de pós-graduação, bem como para validação de diplomas de profissionais estrangeiros que pretendem trabalhar no país” (CELPE-BRAS, 2018).

${ }^{2}$ Esse curso se propôs a atender a demanda de um curso de mestrado acadêmico, que estava recebendo alunos estrangeiros, cuja Língua Materna é o Espanhol, com diferentes formações acadêmicas e faixas etárias, e que necessitavam aulas para a aprendizagem do idioma nacional.
} 


\section{Princípios norteadores de ensino e aprendizagem de Português para estrangeiros}

A proposta de curso de PLE partiu de um convite do coordenador do Instituto de Linguística, Letras e Artes (ILLA) da Unifesspa, para que fosse ministrado um curso de Português Instrumental direcionado a dois acadêmicos estrangeiros vinculados ao Programa de Mestrado em Dinâmicas Territoriais e Sociedade na Amazônia (PDTSA) da PósGraduação da referida IES. Os acadêmicos tinham de aprender a Língua Portuguesa e demonstrar tal conhecimento mediante a realização do Celpe-Bras e a produção de gêneros acadêmicos em Língua Portuguesa no mestrado, incluindo apresentação de uma dissertação em Português, até 2017.

A elaboração do plano de trabalho partiu da ideia de que, conforme Almeida Filho (2015, p. 11):

Professores e alunos não ensinam e aprendem a esmo. Eles são levados a ensinar como ensinam e a aprender como aprendem de um modo ordenado pelas visões que possuem do que lhes parece ser ensinar e aprender uma nova língua e das capacidades para agir (as competências) pela aprendizagem da língua-alvo.

Além disso, assumiu-se que a língua se constitui como um sistema, uma rede de alternativas e escolhas paradigmáticas (HALLIDAY, 1978, p. 2). A linguagem, nesse viés, perpassa a noção de que é um sistema social e semiótico (significação do texto no contexto) usado para cumprir três funções (metafunções) básicas, tal como assevera Halliday e Matthiessen (2004, p.22): 1. representar a experiência - função ideacional ou experiencial; 2. representar a interação entre as pessoas - função interpessoal; 3. representar um discurso que tenha sentido - função textual. Nesses termos, é por meio da linguagem, principalmente por meio de gêneros, isto é, por meio de processos sociais graduais e guiados por objetivos (MARTIN; ROSE, 2008, p. 06) que se materializam através de textos, entendidos como unidades semânticas (HALLIDAY, 1994), que o falante/escritor manifesta sua experiência de mundo e suas relações de forma.

Coerente com essa visão de língua, linguagem, gênero e texto, adota-se a ideia de que uma língua, para ser usada de modo adequado e em diferentes contextos, precisa ser ensinada e envolve um processo que perpassa uma série de ações que abrangem diferentes níveis (ALMEIDA FILHO, 2007; 2012). Nos níveis iniciais de aprendizagem, o esforço é produzir compreensibilidade, com os parcos recursos existentes entre os aprendentes na nova língua. Isso exige que as condições afetivas e emocionais sejam favoráveis. Quando as condições 
internas são positivas e as externas também (clima da aula, material propício, professor acolhedora etc.) existe a probabilidade de aprendizagem. É importante manter uma atmosfera confortável, não tensa, para nela produzir e ouvir a língua usada na sala.

Ademais das visões de linguagem, gênero e texto, cumpre ao professor a definição do método de ensino de linguagem e de atividades de ensino, bem como a seleção e o uso de recursos a serem adotados no exercício da sua função de ensinar qualquer idioma. É sabido que se vive em uma era denominada pós-método, em que não há um modo de ação considerado como o fazer ideal. Nesta era, compete ao professor, portanto, a definição de um método coerente com as concepções de linguagem e de ensino que assume em um contexto de ensino ${ }^{3}$.

Fora do Brasil, podem-se citar os estudos desenvolvidos por pesquisadores do Interacionismo Sociodiscursivo/Sequência Didática (BRONCKART, 1999; 2012; SCHNEUWLY; DOLZ, 2004; SHNEUWLY, 2004) e da Escola de Sydney ${ }^{4} /$ Pedagogia de Gênero (MARTIN; ROSE, 2008; ROSE; MARTIN, 2012). No Brasil, estudos que versam sobre o ensino de línguas com base em gêneros, reportam o uso de diferentes teorias e metodologias de ensino. Dentre eles, destacam-se os estudos desenvolvidos por pesquisadores da Análise Crítica de Gênero (MOTTA-ROTH, 2006; MOTTA-ROTH, 2008; NASCIMENTO, 2017), do Interacionismo Sociodiscursivo associado aos estudos da Escola de Sydney (MUNIZ DA SILVA, 2015; MOREIRA; GALVÃO; ARAÚJO; COSTA, 2016) e da Linguística Sistêmico Funcional associados aos estudos de Martin e Rose (FUZER, 2012; 2014; MUNIZ DA SILVA, 2018).

Interacionismo Sociodiscursivo associado aos estudos da Escola de Sydney pode ser entendida como uma perspectiva de ensino, criada por pesquisadores brasileiros, mediante a associação de conceitos da Escola Francesa e da Escola Australiana em situações de ensino e aprendizagem de linguagem. Com base no Interacionismo Sociodiscursivo, o gênero é "um primeiro sistema de língua, em estreita relação com as redes de atividades humanas e com a sua organização social" (BRONCKART, 2003). Ele se configura como uma forma de ação social, cuja apreensão é condição fundamental para uma inserção adequada em práticas

\footnotetext{
3 Tais opções e ações precisam ser coerentes com os documentos oficiais que regem o ensino no contexto brasileiro.

${ }^{4}$ Segundo a pesquisa de Oliveira e Silva (2018, p.258), “a denominação 'Escola de Sidney’ se refere a um grupo de pesquisadores do Departamento de Linguística da Universidade de Sidney, que desenvolveram projetos de pesquisa sobre a escrita e os gêneros no início dos anos de 1980”.
} 
sociais e comunicativas. O texto é "unidade de ação verbal, oral ou escrita, contextualizada, que veicula uma mensagem linguisticamente organizada e que tende a produzir um efeito de coerência no destinatário" (BRONCKART, 1999, p. 5).

Além disso, a partir do ISD, conforme Stutz e Cristóvão (2011), alguns elementos fundamentais são estabelecidos para a elaboração de materiais didáticos, tais como,

I. apresentação de situações comunicativas; II. elaboração de objetivos claros; III. levantamento de conteúdo apropriado ao gênero em estudo; IV. uso de textos autênticos em circulação na sociedade; V. organização de atividades espiraladas, correspondentes aos objetivos propostos; VI. elaboração de atividades significativas que proporcionem práticas bem-sucedidas de operações de linguagem; VII. desenvolvimento de ações de linguagem (capacidades de ação, discursiva e linguístico-discursiva e de significação envolvidas em diferentes tipos de interação); VIII. aplicação de atividades de compreensão do funcionamento linguístico no gênero textual que está sendo estudado, em associação com as metas a serem atingidas.

A implementação dessas etapas demanda do professor a realização de um estudo prévio com foco na modelização do gênero a ser ensinado, no levantamento de conhecimentos e necessidades dos alunos relativos a esse gênero e na definição de uma sequência didática envolvendo o desenvolvimento de capacidades de linguagem e na produção da lista de constatação.

Em termos teóricos, a modelização do gênero nada mais é do que um estudo prévio do gênero a ser ensinado, realizado por meio de observações guiadas pelas capacidades de linguagem (capacidade de ação, capacidade discursiva e capacidade linguístico-discursiva). Por sua vez, a sequência didática é "[...] um conjunto de atividades escolares organizadas, de maneira sistemática, em torno de um gênero" que "servem para dar acesso aos alunos a práticas de linguagem novas ou dificilmente domináveis" (SCHNEUWLY; DOLZ, 2004, p. 82-83), a qual consiste em apresentação da situação de interação e produção inicial, Módulos / Oficinas e Produção final.

Capacidades de linguagem dizem respeito ao reconhecimento do gênero, do contexto de produção e envolve a mobilização de conteúdo e inclui três tipos de capacidades: 1. a capacidade discursiva, que diz respeito à organização textual geral de cada gênero, aos tipos de discursos e às sequências textuais priorizadas; 2 . a capacidade linguístico-discursiva, a qual está relacionada aos recursos linguísticos que contribuem para a construção do significado do texto como um todo e; 3 . capacidade de significação, a qual corresponde à construção de sentido, de representações e/ ou conhecimentos sobre práticas sociais (contexto ideológico, histórico, sociocultural, econômico etc.) envolvidas nas esferas de atividade, nas atividades 
praxiológicas em interação com conteúdos temáticos de diferentes experiências humanas e suas relações com atividades de linguagem.

Escola de Sydney e os conhecimentos de Linguística Sistêmico-Funcional (LSF) são uma visão de ensino, adotada por pesquisadores brasileiros, que percebe o gênero como uma ferramenta cultural utilizada em dado contexto para alcançar objetivos específicos. Os gêneros são processos sociais e semióticos utilizados pelos sujeitos em práticas sociais em uma determinada cultura.

A fim de analisar e definir os gêneros, os pesquisadores da Escola de Sydney elaboraram a perspectiva tipológica e a topológica de gênero (ROSE; MARTIN, 2012). A primeira sistematiza os gêneros em famílias, e essas famílias são classificadas a partir dos propósitos sociais que são três: envolver, informar e avaliar. Cada família envolve gêneros que compartilham o mesmo propósito social. A título de ilustração, tendo por propósito social avaliar, os argumentos (persuadir) e as respostas (criticar) se configuram em família de gêneros. A família dos argumentos inclui os gêneros exposição e discussão, enquanto a família das respostas a textos abrange os gêneros resenha, interpretação e resposta crítica (cf. ROSE; MARTIN 2012, P. 130).

Nessa visão, a partir do estudo de aspectos gramaticais, os alunos são orientados a perceber os aspectos contextuais (de cultura e de situação) e textuais para depreender o sentido de cada texto. Contexto é um conceito fundamental na Linguística Sistêmico Funcional, oriundo de estudos antropológicos desenvolvidos por Malinowski (HALLIDAY, 1978). Contexto de cultura é mais abrangente e os significados são construídos a partir de cultura, de crenças, conceitos, rituais de uma comunidade, enquanto que o contexto de situação tem a ver com o assunto, com a maneira como as pessoas se relacionam e estruturam seus textos (FUZER; CABRAL, 2014). O texto é um material da língua de qualquer extensão, que é organizado em partes, tem sentido, coesão e coerência. O ensino nessa perspectiva se efetiva a partir do funcionamento de uma Pedagogia de Gênero que pode começar com a desconstrução de textos, passar pela construção coletiva de um texto e finalizar com a construção individual de um texto.

No ensino de Português como Língua Estrangeira (PLE), área que compreende as três ciências da Linguagem, a saber, a Estética da Linguagem, englobando a tradicional área das literaturas e sua teorização, a Linguística, referindo-se aos estudos da estrutura e funcionamento da linguagem humana, e os Estudos Aplicados ou Linguística Aplicada, 
produzidos a partir de investigações de natureza aplicada sobre questões de linguagem na prática social (ALMEIDA FILHO, 2015). É notório o uso de procedimentos de ensino de gêneros orientados por estudos do ISD e do Ensino de Idioma Instrumental, envolvendo o ensino de estratégias de leitura. No que diz respeito ao Ensino de Idioma Instrumental e ao ensino de estratégias de leitura, as aulas são distribuídas em três partes e envolvem, conforme Aebersold e Field (1997), as fases de pré-leitura, de leitura propriamente dita e de pós-leitura.

$\mathrm{Na}$ sequência, apresenta-se o plano de trabalho articulado com base nas abordagens linguagem, de ensino de linguagem e de PLE apresentadas até aqui.

\section{Um plano de trabalho para o ensino de gêneros acadêmicos}

Na elaboração e desenvolvimento do plano do curso intitulado como "Oficinas de Letramento na Academia: Leitura, Escrita e Análise Linguística de Gêneros Discursivos”, perpassou a visão de linguagem como interação, a noção de gênero como ação social estruturada em etapas para atingir uma finalidade e mesclaram-se noções de ensino de leitura instrumental, de gêneros discursivos do ISD e da Escola de Sydney, com foco no ensino de gêneros que circulam em ambiente acadêmico.

O curso envolveu quatro módulos e incluiu os gêneros biografia, carta aberta, artigo de opinião e crítica de filmes, por apresentarem características que estabelecem relação com gêneros usados no meio acadêmico. No desenvolvimento de cada módulo, foram realizadas três oficinas. Cada oficina compreendeu 10h de aula, sendo $3 \mathrm{~h}$ presenciais e $1 \mathrm{~h}$ a distância (atividades de casa). No total, o curso compreendeu 40h de trabalho e envolveu a realização de oficinas de desconstrução/leitura, construção coletiva e individual de textos em Língua Portuguesa, circunscritas aos gêneros mencionados. Cada oficina foi dividida em três momentos e envolveu atividades de pré-leitura, leitura/análise/desconstrução de gêneros e pós-leitura, tal como consta no Quadro 1:

Quadro 1 - Oficinas e momentos

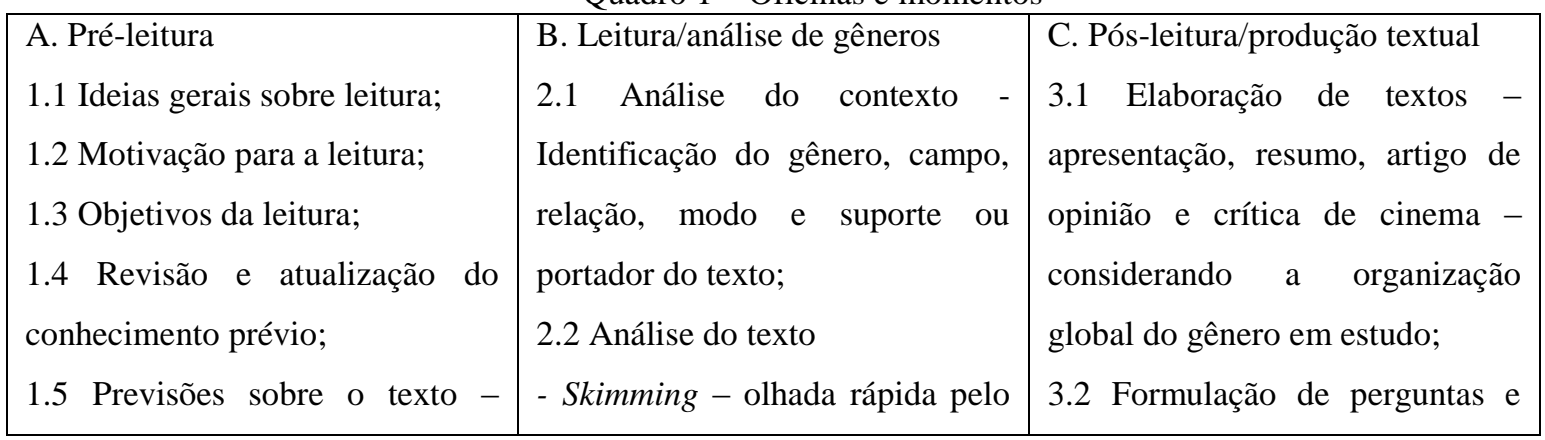




\begin{tabular}{|c|c|c|}
\hline $\begin{array}{l}\text { antecipação do que vem em } \\
\text { seguida ao que está sendo lido. }\end{array}$ & $\begin{array}{l}\text { texto, por meio da identificação } \\
\text { de palavras cognatas, ilustrações, } \\
\text { diagrama, tabelas, saliências } \\
\text { gráficas ou pistas tipográficas, } \\
\text { títulos, subtítulos, legendas, para } \\
\text { ter uma ideia geral do assunto } \\
\text { tratado; } \\
\text { - Scanning - leitura rápida para } \\
\text { localizar alguma informação } \\
\text { específica no texto; } \\
\text { - Exploração dos tipos textuais e } \\
\text { das articulações na superfície } \\
\text { textual; } \\
\text { - Identificação da ideia principal; } \\
\text { - Exploração de pistas textuais - } \\
\text { pronomes, } \\
\text { articuladores etc.; } \\
\text { - Construções de elos coesivos - } \\
\text { lexicais e gramaticais; } \\
\text { - Reconhecimento de palavra- } \\
\text { chave para construir a progressão } \\
\text { temática; } \\
\text { - } \\
\text { vozes/intertextualidade; } \\
\text { - Construção de inferências. }\end{array}$ & $\begin{array}{l}\text { respostas sobre o que foi lido; } \\
3.3 \text { Esclarecimento de possíveis } \\
\text { dúvidas; } \\
\text { 3.4 Leitura crítica e re-escritura } \\
\text { dos textos. }\end{array}$ \\
\hline
\end{tabular}

Fonte: Professores responsáveis pela organização do Curso.

Ao longo da realização do trabalho, o objetivo geral foi fornecer meios para a desconstrução e construção de textos em Língua Portuguesa, visando à formação de um leitor mais crítico, que estabelece objetivos e relaciona aspectos textuais e contextuais ao realizar leituras, e um produtor de texto mais consciente.

Na prática, no período de três meses, envolvendo o período de dezembro de 2015 a fevereiro de 2016, o curso foi coordenado pela Profa. Dra. Tânia Maria Moreira e ministrado, por alunas em formação e bolsistas do curso de Letras Português (Anna Caroline Ribeiro, Camila Solino e Jéssica Freire) e por uma professora substituta do curso de Inglês (Prof. ${ }^{a}$ Me. LaissyTaynã Barbosa) da Unifesspa, que atuaram de modo colaborativo. 
A partir da proposta do curso, foram elaborados planos de aulas, que incluíram objetivos específicos distintos e procedimentos avaliativos. As avaliações perpassaram pela observação constante do desenvolvimento dos alunos, mediante a participação nas aulas e a realização de atividades em sala de aula (colaborativamente) e em casa (individualmente).

\section{Encaminhamentos e resultados alcançados}

Inicialmente, as aulas contaram com a participação de dois alunos do mestrado acadêmico do PDTSA, ambos de nacionalidade peruana, sendo um graduado em Jornalismo e o outro em Geografia. O aluno A1 participou de forma presencial do curso, enquanto o aluno A2, por estar ausente da cidade durante o período das aulas, acompanhou de forma digital, através das redes sociais, videoconferências, e-mails etc.

Logo após o início do curso, uma aluna (A3) cubana, estudante do pós-doutorado, também no PDTSA, e graduada em Filosofia, assim que tomou conhecimento do curso, demonstrou interesse pela proposta e passou a participar das aulas, inclusive realizou todas as atividades propostas.

As aulas ocorreram uma vez por semana na Unifesspa, contaram com materiais didáticos adaptados ou elaborados pelas professoras e bolsista responsáveis que levaram em consideração a língua materna dos alunos, o Espanhol, assim como suas diferentes formações acadêmicas e faixas etárias, visando aprimorar conhecimentos de linguagem, de leitura e de produção textual dos estudantes, atendendo à demanda de suas necessidades acadêmicas, com foco maior na preparação para a avaliação do Celpe-Bras.

Uma breve análise do material didático produzido para esse curso de PLE indica que, essa proposta de ensino de língua seguiu as etapas da pedagogia de gênero, semelhante ao utilizado pela Escola de Sidney, que integram propostas de análise do texto (desconstrução), assim como a sua produção (construção) de forma coletiva e individual.

As pesquisas realizadas por essas autoras indicam ainda que os pesquisadores dessa corrente australiana seguem uma perspectiva em que o conhecimento se embasa através de propostas de leitura e de escrita com base em gêneros, constituindo-se assim em um "[...] franco espaço institucional de reflexão sobre o uso da língua nos diversos contextos sociais" (OLIVEIRA; SILVA, 2018, p. 252 e 253). O trabalho desenvolvido por esses pesquisadores tem como base os pressupostos teóricos da Linguística Sistêmico-Funcional (LSF), que segundo as autoras: 
[...] é uma abordagem semântico-funcional de linguagem, que investiga como as pessoas usam a linguagem em diferentes contextos e como a linguagem é estruturada para o uso como sistema semiótico. [...] Na LSF, estudamos a língua e sua relação com o contexto social como sistemas semióticos que se realizam um no outro. Isso significa que o contexto social influencia o surgimento de padrões de língua e que a língua constrói e é construída pelo contexto social (OLIVEIRA; SILVA, 2018, p.252).

Durante os módulos deste curso de PLE, a proposta de ensino também incluiu princípios do ISD na medida em que foram organizadas atividades que contemplaram, primeiro, a apresentação de uma proposta de escrita, incluindo seus objetivos, os gêneros textuais a serem produzidos e o público-alvo dos textos, seguido de uma produção inicial; além de oficinas de leitura com a finalidade de desenvolver as capacidades de ação, discursivas e linguístico-discursivas dos alunos e, por fim, promover a produção final e a publicação das produções na comunidade acadêmica. Conforme Oliveira e Silva (2018, p. 270),

na abordagem de gêneros da "Escola de Sydney", a sistematização dos gêneros é construída com base no propósito social do texto e suas regularidades léxicogramaticais, por isso há uma terminologia distinta daquela comum na tradição das escolas brasileiras. Além disso, os gêneros não são vistos individualmente, mas nas relações que estabelecem entre si. O texto materializa-se como um artigo de opinião, mas se enquadra como um gênero argumentativo.

A título de exemplo, ao longo do módulo 3, os alunos estudaram o gênero artigo de opinião, que integra a família dos gêneros argumentativos de exposição, conforme proposta da abordagem sistêmico-funcional para análise de textos (MARTIN; ROSE, 2007; ROSE; MARTIN, 2012; ROSE, 2013).

Conforme Oliveira e Silva (p.270, 2018), esse gênero textual pode ser entendido como "uma resposta crítica a outros textos, o qual irá avaliar e argumentar um ponto de vista, baseado em evidências, externando sentimentos, julgamentos ou interpretações particulares". Ainda segundo as autoras, compreende-se que o ensino da argumentação deve seguir uma perspectiva dialógica, para que se possa acionar o pensamento crítico do aluno e permiti-lo perceber "[...] que os textos se relacionam em uma grande cadeia, ao selecionarem pontos de vista que necessariamente serão defendidos ou negados implícita ou explicitamente" (OLIVEIRA; SILVA, p.271, 2018).

Para as autoras, os gêneros, as etapas e fases se relacionam de forma composicional e realizacional, ou seja, o gênero é composto de etapas, que elas classificam como "segmentos textuais previsíveis", as etapas se constituem de fases, classificadas como "segmentos 
variáveis em cada etapa do gênero" e, por fim, as fases "[...] consistem de mensagens (concretizadas em orações simples, coordenadas e subordinadas)" (ROSE, 2016 apud OLIVEIRA; SILVA, p. 271, 2018).

Em continuidade a esses aspectos apresentados sobre o gênero, é válido destacar que

O gênero exposição é constituído das etapas Tese, Argumentos e Reiteração. A Tese apresenta o ponto de vista a ser defendido; os Argumentos são recursos linguísticos ou semióticos que levam o interlocutor a aceitar o que está sendo defendido, podendo aparecer indefinidamente, sendo marcados como Argumento 1, Argumento 2, Argumento N, de acordo com a necessidade apresentada no texto; a Reiteração é a etapa em que a tese é retomada e reafirmada. As fases dos textos argumentativos constroem o suporte aos argumentos e ancoram-se em tópicos-frasais (que podem realizar-se por declaração inicial, definição, divisão, alusão histórica, interrogação) e em evidências (alusão a fato, citação, enumeração de detalhes, confronto, analogia e comparação, exemplos, causação, explanação, elaboração, comentário) (OLIVEIRA; SILVA, 2018, p.272).

Para as autoras ${ }^{5}$, nos gêneros argumentativos, o tópico frasal ${ }^{6}$, sendo esse uma frase apresentada no início ou no fim do parágrafo, irá expressar "a síntese do pensamento do autor".

Por fim, as pesquisadoras mencionadas apontam que "[...] o desenvolvimento do parágrafo do gênero expositivo realiza-se pela apresentação de algum tipo de evidência: fato, citação, enumeração de detalhes, confronto, analogia e comparação, exemplo, causalidade, explanação, elaboração, comentário" (GARCIA, 1999; HALLIDAY e MATTHIESSEN, 2014 apud OLIVEIRA; SILVA, p.273, 2018).

Com base nessas noções sobre o artigo de opinião e nas lacunas de conhecimentos apresentados na primeira produção escrita dos alunos do curso, a proposta de ensino contemplou os seguintes objetivos: 1. debater temas, construir, reconstruir e compartilhar informações e conhecimentos, a partir de elementos provocadores específicos, considerando as características próprias de artigos de opinião; 2. reconhecer as características do artigo de opinião, partindo de conhecimentos prévios do gênero, passando pela leitura de informações

\footnotetext{
${ }^{5}$ Com base em Rose e Martin (2012), Rose (2007), Martin e Rose (2008), Garcia (1967[2010]), Meyer (2008), Fiorin (2015), Adam (2008) e Muniz da Silva (2015).

${ }^{6}$ [...] O tópico-frasal pode realizar-se por meio de uma declaração inicial (afirmação ou negação a ser justificada ou fundamentada posteriormente), definição (estratégia didática que explicita conhecimento sobre o tema), divisão (apresentação de uma ideia de modo a distinguir seus elementos ou aspectos fundamentais), alusão histórica (referência a fatos históricos, lendas, tradições, acontecimentos ou incidentes do cotidiano) ou interrogação (estratégia persuasiva em que o autor inicia com uma pergunta, devendo respondê-la necessariamente) (OLIVEIRA; SILVA, p. 273, 2018).
} 
divulgadas por especialistas da área da linguagem na perspectiva de ensino de gêneros discursivos e pela análise de texto, considerando aspectos relativos à forma e à função; 3 . publicar o artigo de opinião elaborado pelos alunos em um jornal local da cidade.

No desenvolvimento das aulas, no primeiro momento, os alunos foram convidados a apresentar, oralmente, o que sabiam sobre o artigo de opinião. Enquanto eles apresentavam os conhecimentos sobre o gênero, algumas informações foram registradas em um quadro branco disponível na sala. Em seguida, feita uma breve introdução do gênero artigo de opinião, em termos de forma e função, foi lido um texto ( $O$ chip a laser, de Duda Teixeira) em sala de aula. Nesse momento, a atividade visava a desconstrução, em conjunto, de aspectos do contexto de produção do texto, verificar o possível objetivo do texto e algumas marcas linguísticas que caracterizavam cada parte do gênero em estudo. No final da leitura, os alunos foram questionados em que medida o texto lido poderia ser identificado como artigo de opinião. Por fim, os alunos receberam mais um texto (Entre riscos e benefícios, deJorge Werthein) com a finalidade de que, individualmente, cada aluno reconhecesse no texto o nome do autor, o local de publicação, o possível público-alvo, a função e a forma textual, bem como que procurasse algumas características linguísticas próprias do gênero em estudo.

Em um segundo momento, foram apresentados aos alunos cinco textos (Embriões no Supremo, publicado na Folha de S. Paulo; Não à pesquisa: o sono da razão e a biotecnologia, de Dalton L. P. Ramos; Anos perdidos, de Jerônimo Teixeira; A devoração da esperança no próximo, de Jurandir F. Costa) para que identificassem o gênero (editorial, resenha e um artigo assinado) e estabelecessem relação com o artigo de opinião, contrastando-o com outros gêneros semelhantes. Nessa aula, o objetivo se configurou em ler com a finalidade de observar aspectos contextuais (quem escreve, porque escreve e para quem escreve) e textuais - marcas linguísticas que denotavam as características formais e funcionais, em termos de semelhanças e diferenças. Para alcançar esse objetivo, ao longo das aulas desse módulo, os alunos tiveram contato com diversos artigos e realizaram atividades de observação da linguagem e de compreensão de textos.

Por fim, em um terceiro momento, os alunos foram desafiados a ler o texto $A$ revolução Gourmet, de Glauco Lima com a finalidade de responder nove perguntas (1. Qual a situação de comunicação vivenciada no texto?; 2. Este texto é um artigo de opinião? Se sim, qual a questão polêmica?; 3. Qual a posição do autor?; 4. Quais os pontos de vista contrários aos seus? Onde e de quem são as vozes dos opositores ao texto?; 5. Há vozes favoráveis ao 
texto?; 6. Como identificar os argumentos no texto?; 7. O texto apresenta, ou não, argumentos convincentes?;8. Com que finalidade o autor escreve?; e 9. Como o autor introduz, desenvolve e encerra o artigo?) e identificar algumas informações comunicacionais e estruturais presentes no texto para, então, produzir um artigo de opinião: “Agora é a sua vez de produzir o seu artigo de opinião. Considere que você irá escrever para o jornal Opinião de Marabá como um mestrando da Unifesspa e tomará uma posição ao escrever. Nesse sentido, qual é o seu tema? Como será a sua introdução? Como identificará os argumentos? E a conclusão? Qual será a sua finalidade ao escrever?". Nessa etapa foram realizadas atividades de escrita e reescrita de suas produções.

Ao final do módulo, os alunos A1 e A3 produziram um artigo de opinião cada ${ }^{7}$, que foram publicados, nos dias 28 e 29 de abril de 2016, em um jornal de grande circulação na cidade de Marabá. Integrando os resultados do curso, além da publicação dos artigos, os alunos A1 e A2 obtiveram aprovação no exame do Celpe-Bras, cumprindo assim um dos requisitos obrigatórios para a conclusão da pós-graduação no país.

\section{Considerações finais}

A partir dessa experiência, pode-se pontuar que existe a necessidade de realização e divulgação de mais pesquisas vinculadas ao ensino de PLE, visando um maior preparo dos docentes que trabalham nessa área, tendo em vista que a socialização de trabalhos em eventos que integram essa linha de pesquisa e de ensino, tal como os relatos de diversos professores com experiência na área do PLE, revelam que as primeiras experiências vividas partem, geralmente, de uma demanda da instituição de ensino, que disponibiliza pouco tempo de preparo, fazendo com que o professor pesquise sobre a área simultaneamente com a realização da prática de ensino. Apesar do sucesso e da aprendizagem (de ambos, docente e aluno) obtidos ao final da experiência, essa falta de suporte teórico a priori causa uma certa insegurança ao professor e gera dificuldades ao longo do processo, que poderiam ser facilmente evitadas com o fortalecimento da pesquisa sobre Português para estrangeiros durante a graduação, assim como nos cursos de pós-graduação, na organização de eventos, na produção e popularização de artigos acadêmicos etc.

\footnotetext{
${ }^{7}$ Consta, em anexo, os textos publicados de A1 e A3.
} 
Em decorrência dessas reflexões é importante salientar que o ensino de PLE vai ao encontro de processos sociais em curso no Brasil, como a internacionalização do Ensino Superior (proposta pelo Programa Idiomas sem Fronteiras) e outras ações desenvolvidas nesse âmbito de ensino envolvendo a população de imigrantes que o Brasil recebe e tende a receber em número cada vez mais elevado (CUNHA et al, 2017). Nesse sentido, mostra-se importante que as universidades estejam preparadas, de antemão, para atender a essa demanda e incentivem pesquisas e propostas de ensino de PLE que incluam diversas finalidades, seja para fins acadêmicos, de acolhimento de estrangeiros, de aprendizagem de segunda língua, de formação de professores etc.

\section{Referências Bibliográficas}

AEBERSOLD, J. A. e FIELD, M. L. From reader to reading teacher. New York: Cambridge University Press, 1997.

ALMEIDA FILHO, J. C. P. Índices nacionais de desenvolvimento do ensino de português língua estrangeira. In: ALMEIDA FILHO, José. C. P.; CUNHA, Maria. J. C (Orgs.). Projetos iniciais em português para falantes de outras línguas. Campinas, SP: Pontes, 2007.

ALMEIDA FILHO, J. C. P. Quatro estações no ensino de línguas, Pontes, 2012.

ALMEIDA FILHO, J. C. P. Dimensões Comunicativas do Ensino de Línguas. Campinas, SP: Pontes Editores, $8^{\text {a }}$ Edição, 2015.

BRONCKART, J. P. Atividade de linguagem, textos e discursos: por um interacionismo sócio-discursivo. Trad. Anna Rachel Machado, Pericles Cunha. São Paulo: Educ., [1997, 1999, 2003] 2012.

CAPES. Programa Institucional de Internacionalização - CAPES - PrInt. Brasília: Fundação Capes, 2017. Disponível em: http://www.capes.gov.br/cooperacaointernacional/multinacional/programa-institucional-de-internacionalizacao-capes-print Acesso em: 26 Jul. 2018.

CELPE-BRAS. Celpe-Bras 2018. Brasília: MEC-Inep, 2018. Disponível em: http://celpebras.inep.gov.br/inscricao/ Acesso em 13 Nov. 2018.

CUNHA, M. I. da et al. Estudantes africanos em universidades brasileiras: os desafios da internacionalização "às avessas" no cotidiano universitário. Educação, Porto Alegre, v. 40, n. 3, p. 469-480, set./dez. 2017.

FUZER, C.; CABRAL, S. R. S. Introdução à Gramática Sistêmico-Funcional em Língua Portuguesa. 1. ed. Campinas, SP: Mercado de Letras, 2014. v. 1. 228p. 
FUZER, C. Ateliê de textos: (Re)invenção e (re)escrita de histórias no ensino básico. Revista da ANPOLL (Online), v. 1, p. 56-79, 2014.

GARCIA, O. M. Comunicação em prosa moderna. 17. ed., reimpressão. Rio de Janeiro: Editora FGV, 1999.

GARCIA, O. M. Bilhete orientador como instrumento de interação no processo ensinoaprendizagem de produção textual. RevistaLetras (UFSM) online, v. 22, p. 213-245, 2012.

HALLIDAY, M. A. K. Language as a social semiotic: the social interpretation of language and meaning. Londres: Edward Arnold, 1978.

HALLIDAY, M. A. K. An introduction to functional grammar. Londres: Edward Arnold, 1994.

MARTIN, J.; ROSE, D. Genre Relations: Mapping Culture. London: Equinox, 2008.

MOREIRA, T. M.; GALVAO, A. P.; ARAÚJO, m. do L. P; COSTA, M. S. Análise de Propostas Didáticas para o Ensino de Língua Materna na Perspectiva de Gêneros Discursivos/ Textuais. In: Wagner Rodrigues Silva, Paulo da Silva Lima, Tânia Maria Moreira. (Org.). Gêneros na prática pedagógica: diálogos entre escolas e universidades. 1 ed. Campinas - SP: Pontes Editores, 2016, v. 1, p. 229-257.

MOTTA-ROTH, D. Ensino de produção textual com base em atividades sociais e gêneros textuais. Linguagem em (Dis)curso - LemD, Tubarão, v. 6, n. 3, p. 495-517, set./dez. 2006.

MOTTA-ROTH, D. Para ligar a teoria à prática: roteiro de perguntas para orientar a leitura/análise crítica de gênero. In: D. Motta-Roth, T. Cabañas and G. R. Hendges. Análise de textos e discursos: relações entre teorias e práticas. Santa Maria, BR: PPGL Editores, 2008.

MUNIZ DA SILVA, E.C. Ciclo de aprendizagem baseado em gêneros. Linguagem, estudos e pesquisas (UFG), v. 19, p. 19-36, 2015.

MUNIZ DA SILVA, E.C. Gêneros na teoria sistêmico-funcional. DELTA. Documentação de Estudos Em Linguística Teórica e Aplicada (PUC-SP. IMPRESSO), v. 34, p. 305-330, 2018.

NASCIMENTO, R. G.. Análise crítica de gênero, planejamento de material didático e letramentos do professor de inglês como língua estrangeira/adicional. In: TOMITCH, Lêda M.B.; HEBERLE, Viviane M.. (Org.). Perspectivas atuais de aprendizagem e ensino de línguas. 1 ed. Florianópolis: LLE/PPGI/UFSC, 2017, v. 1, p. 121-152.

OLIVEIRA, K. C. N. de; SILVA, E. C. M. da. Reflexões para o ensino de gêneros em Língua Portuguesa: contribuições da 'Escola de Sidney'. In: ALMEIDA, Fabíola A. S. D. P.; XAVIER, Vanessa R. D. (orgs.). Diálogos e perspectivas nos estudos do léxico e formação de professores. 1 ed. Campinas: Mercado Letras, 2018. p. 249-298.

ROSE, D.; MARTIN, J. Learning to Write, Reading to Learn: Genre, Knowledge and Pedagogy in the Sydney School. London: Equinox, 2012. 
SCHNEUWLY, B. \& DOLZ, J. Os gêneros escolares - as práticas de linguagem aos objetos de ensino. In: Schneuwly, B.; Dolz, J. Gêneros orais e escritos na escola. Campinas, SP: Mercado de Letras, [1997] 2004.

STUTZ, L.; CRISTÓVÃO, V. L. L. A construção de uma sequência didática na formação docente inicial de Língua inglesa. Signum. Londrina: UEL, n. 4, p. 569-589, jun. 2011.

\section{Anexos}

Figura 1 - Artigo dos Alunos A1 (esq.) e A3 (dir.) publicados no jornal.

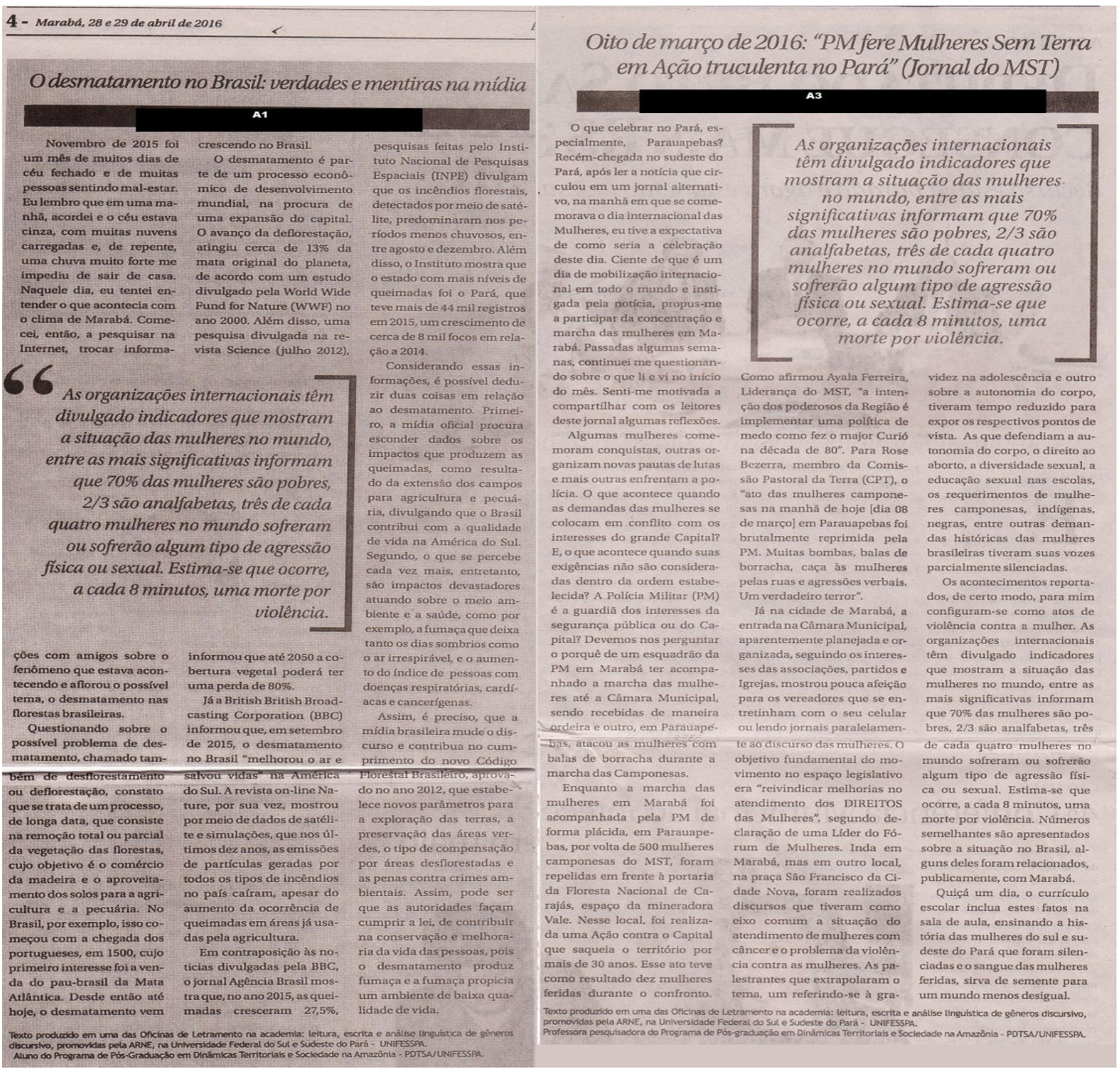

Fonte: extraído do jornal Opinião. 